\title{
STRUCTURAL FIRE SAFETY OF EXISTING STEEL BUILDINGS Possible general approach and application to the case of the intumescent coatings
}

\author{
Antonio Bilotta, Donatella de Silva, Emidio Nigro \\ University of Naples - Federico II, DIST - Department of Structures for Engineering and Architecture, Naples, Italia
}

\begin{abstract}
The fire safety of the existing structures is very important from the socio-economic point of view and has high social impact for civil, industrial, and commercial buildings. The verification of the minimum fire resistance of civil structures is done through some regulations, drafted to ensure occupant and rescue teams safety as well as a limited structural damage. These national fire rules are not always easily applicable to existing buildings.

The purpose of this paper is to provide guidance about the structural analysis of existing buildings exposed to fire, with particular reference to steel buildings protected with intumescent coatings.
\end{abstract}

Keywords: existing buildings, intumescent coating, experimental tests, thermal behaviour

\section{INTRODUCTION}

In order to limit the risks from fires, the buildings must be designed and built to ensure the strength and stability and to limit the spread of fire and smoke, as required by fire regulations (CEE, Interpretative Document No. 2: Safety in case of fire, 1993)0.

The performance of fire resistance requirements for structures are currently modulated, in the Eurocode (EN 1993-1-2), in different performance levels in order to ensure that the possible structural damage has not unacceptable consequences for the safety of occupants and rescue teams.

The Eurocodes do not provide specific guidances for the assessment of structural vulnerability of existing buildings in fire situations, but this topic is very important from the socio-economic point of view and has high social impact for civil, industrial, and commercial buildings.

On the other hand, specific regulations concern seismic retrofitting of existing buildings. In this regard, Eurocode 8 defines information necessary for the assessment of the seismic vulnerability, with reference to:

-design documents or any documentations acquired after the construction;

-data from structural surveys;

-results of tests on structural elements (in situ);

-results of tests conducted in the laboratory on samples taken from the existing structure.

In addition, the Eurocode defines different degrees of uncertainty (level of knowledge) on the structural geometry and the materials mechanical properties. Moreover, it suggests both type and minimum number of tests and surveys required to achieve a knowledge level. Finally, based on this knowledge level, it identifies analysis methods and partial safety factors for the materials properties to be used in the structural analysis. Therefore, the approach suggested by the Eurocode for verification of seismic vulnerability can be a useful reference for the definition of a procedure for evaluating the structural safety in fire conditions of existing buildings.

\section{CRITERIA FOR THE ASSESSMENT}

For the vulnerability assessment of existing buildings in fire conditions there are no approaches and procedures, whereas prescriptive and performance based approaches are provided for new structures. However, these approaches could be properly adapted for existing structures.

The prescriptive based approach establishes a series of rules and requirements to guarantee a predetermined resistance with immediacy and simplicity of calculation (tabular data, simple analytical models, certified products and systems); moreover, the thermo-mechanical analysis refer 
to the standard fire curve (ISO834) (EN 1363-2). The performance based approach consists of more detailed analysis of the fire, considering natural fire curves, which combine more sophisticated calculation (advanced methods) for structural models.

Therefore, the choice of the verification method for existing buildings affect the target of the knowledge level of the structure: there is a strong correlation between the verification methods and the informations that you need to get from papery and digital documents of design and maintenance certifications, or from results of tests in situ and / or in laboratory. The level of detail required for prescriptive based approach is lower than that required for the performance based one.

As for static and seismic assessment, for the fire resistance assessment, it is necessary to characterize the structural materials, namely steel profiles and reinforcing bars as well as the concrete. In addition, it is necessary to characterize the thermo-mechanical properties of the structural materials and to define the presence and the effectiveness of any fire protection systems, whether reactive or passive. Therefore, an approach for the evaluation of existing buildings during fire can be obtained by integrating the general approach, suggested by the Eurocode for the safety assessment of existing buildings, with more details on the verification of structures in fire conditions.

The tables 1 and 2 summarize the suggestions for the characterization of the structure, the structural materials and the protective materials, through certifications and tests in situ or in laboratory.

A simplified analysis (e.g. by prescriptive based approach with simplified and tabular methods) can be performed with a basic knowledge of structural details. If constructional details are incomplete, information should be integrated with limited testing in situ (limited means at least about 15\% of the elements). If details are available, only a random visual survey is necessary to check their compliance with the real structure. For advanced analysis (performance based approach) a more complete knowledge of the structure is obviously necessary. If the structural details are fully available, only limited checks in situ are necessary (limited means that the geometry and the characteristics of the connections are verified for at least $15 \%$ of the elements). Otherwise it is necessary to carry out extended checks in situ (extended means at least on $35 \%$ of the elements). For the mechanical properties of the structural materials, the original design specifications and the original test certificates can be integrated with limited tests in situ (e.g. 1 steel specimen for each floor of the building, 1 sample of bolt or nail for each floor of the building, 1 destructive test or more non-destructive tests for concrete). In absence of certification, it is necessary to carry out extensive tests in situ (e.g. 2 steel specimens for each floor of the building, 2 samples of bolts or nails for each floor of the building, 2 destructive tests or more non-destructive tests for concrete).

For protective slabs (ceilings, screens and plates) are suggested (UNI 10898-2) : thickness tests, in situ;

- $\quad$ tests on density, conductivity, specific heat (in situ and / or in laboratory);

- $\quad$ tests of fire resistance on samples taken from the existing structure, in laboratory.

Sometimes the fire protection systems are built with links and joints; in this case, if necessary, specific tests on each part or on the whole protective system should be performed.

For insulating sprayed systems are suggested (UNI 10898-3):

- $\quad$ thickness tests, in situ;

- $\quad$ measures of adhesion / cohesion, in the laboratory and in situ;

- $\quad$ tests on density, conductivity, specific heat in situ and / or in laboratory;

- $\quad$ tests in furnace on samples taken from the existing structure, in laboratory;

- $\quad$ tests of fire resistance, on samples taken from the existing structure, in laboratory;

Again, tests on any accessories and finishes should be performed, in accordance with UNI 10898-3.

In the case of intumescent paints are suggested:

- $\quad$ thickness tests, in situ (UNI 10898-1);

- $\quad$ measures of adhesion / cohesion, in laboratory and in situ;

- $\quad$ tests in furnace (with standard and smouldering curves) of samples taken from the existing structure, in laboratory (EN 13381-8);

- $\quad$ tests of fire resistance, on samples taken from the existing structure, in laboratory;

- $\quad$ evaluation of stickability. 
Regulations (EN 13381-8) about the tests listed above, refer to the verification of the product after installation.

It is worth to note that for the tests in the furnace (which obviously must be carried out in laboratory) there is the problem of take samples from the structure, especially when they are structural elements (Wald et al.).

During the life of the structure, careful maintenance is needed for the intumescent paint, through periodic inspections finalized to certificate its integrity. In this case, could be necessary to verify that the paint maintains its characteristics of reactivity (swelling with high temperatures) through in situ tests, with proper tools, which can concentrate the heat in a limited area (Rush et al., 2014). For this reasons, a test procedure (in situ or in laboratory) would be desirable.

If all certifications of the protections are available, both simplified approaches (tabular method, analytical method, experimental method) and more sophisticated methods provided by the performance based approach can be used. Else, the tests and surveys indicated in Tables 1 and 2 should be performed.

Table 1. Definition of geometry and material characterization.

\begin{tabular}{|c|c|c|c|c|c|}
\hline \multirow{2}{*}{$\begin{array}{l}\text { Methods of } \\
\text { analysis }\end{array}$} & \multirow{2}{*}{ Geometry } & \multirow{2}{*}{ Structural details } & \multirow{2}{*}{$\begin{array}{c}\text { Properties of } \\
\text { materials }\end{array}$} & \multicolumn{2}{|c|}{ Properties of fire protections } \\
\hline & & & & passive, reactive & active \\
\hline Tabular & \multirow{4}{*}{$\begin{array}{l}\text { From original } \\
\text { outline } \\
\text { construction } \\
\text { drawings with } \\
\text { sample visual } \\
\text { survey } \\
\text { or } \\
\text { from full } \\
\text { survey, } \\
\text { including all } \\
\text { systems for fire } \\
\text { protections }\end{array}$} & Unnecessary & Unnecessary & \multirow[b]{2}{*}{$\begin{array}{l}\text { From incomplete design } \\
\text { documentations } \\
\text { (certificates of tests and } \\
\text { of correct application, } \\
\text { technical documentations } \\
\text { and maintenance } \\
\text { manuals) with limited in- } \\
\text { situ testing } \\
\text { or } \\
\text { extended in-situ testing. }\end{array}$} & \multirow[b]{2}{*}{$\begin{array}{c}\text { From incomplete design } \\
\text { documentations (test } \\
\text { certificates, system } \\
\text { diagrams, technical } \\
\text { documentations and } \\
\text { user and maintenance } \\
\text { manuals) with limited } \\
\text { in-situ testing } \\
\text { or } \\
\text { extended in-situ } \\
\text { testing. }\end{array}$} \\
\hline Analytical & & $\begin{array}{l}\text { From incomplete } \\
\text { original detailed } \\
\text { construction drawings } \\
\text { with limited in situ } \\
\text { inspection } \\
\text { or } \\
\text { from extended in-situ } \\
\text { inspection. } \\
\\
\text { From complete } \\
\text { original detailed } \\
\text { construction drawings } \\
\text { with sample visual } \\
\text { survey }\end{array}$ & \multirow{3}{*}{$\begin{array}{l}\text { From original } \\
\text { design } \\
\text { specifications } \\
\text { with limited } \\
\text { in-situ testing } \\
\text { or } \\
\text { from } \\
\text { extended in } \\
\text { situ testing }\end{array}$} & & \\
\hline Advanced & & $\begin{array}{l}\text { From original detailed } \\
\text { construction drawings } \\
\text { with limited in situ } \\
\text { inspection } \\
\text { or } \\
\text { from comprehensive } \\
\text { in situ inspection }\end{array}$ & & $\begin{array}{l}\text { From complete design } \\
\text { documentations } \\
\text { (certificates of tests and } \\
\text { of correct application, } \\
\text { technical documentation } \\
\text { and maintenance manual) } \\
\text { with limited in-situ } \\
\text { testing } \\
\text { or } \\
\text { from comprehensive in- } \\
\text { situ testing }\end{array}$ & $\begin{array}{l}\text { From complete design } \\
\text { documentations (test } \\
\text { certificates, system } \\
\text { diagrams, technical } \\
\text { documentation and user } \\
\text { and maintenance } \\
\text { manual) with limited } \\
\text { in-situ testing } \\
\text { or } \\
\text { from comprehensive } \\
\text { in-situ testing }\end{array}$ \\
\hline Tests & & - & & New characterization & - \\
\hline
\end{tabular}


Table 2 - Tests required for the characterization of protective materials.

\begin{tabular}{|c|c|c|c|c|c|}
\hline \multirow{2}{*}{ Protection } & \multicolumn{3}{|c|}{$\begin{array}{c}\text { Coatings } \\
\text { for passive protection }\end{array}$} & \multicolumn{2}{c|}{$\begin{array}{c}\text { Membranes } \\
\text { for passive protection }\end{array}$} \\
\cline { 2 - 6 } & Sprayed systems & Boards & $\begin{array}{c}\text { Intumescent } \\
\text { coatings }\end{array}$ & Countertop & Screen \\
\hline Thickness tests & $\checkmark$ & $\checkmark$ & $\checkmark$ & $\checkmark$ & $\checkmark$ \\
\hline Adhesion/cohesion tests & $\checkmark$ & $X$ & $\checkmark$ & $X$ & X \\
\hline Resistance tests on links & X & $\checkmark$ & $X$ & $\checkmark$ & $\checkmark$ \\
\hline $\begin{array}{c}\text { Characterization of density, } \\
\text { conductivity, specific heat }\end{array}$ & $\checkmark$ & $\checkmark$ & $X$ & $\checkmark$ & $\checkmark$ \\
\hline $\begin{array}{c}\text { Tests in furnace on samples } \\
\text { taken from the existing } \\
\text { structure }\end{array}$ & $\checkmark$ & $\checkmark$ & $\checkmark$ & $\checkmark$ & $\checkmark$ \\
\hline $\begin{array}{c}\text { Tests in furnace of whole } \\
\text { system }\end{array}$ & $\mathrm{X}$ & $\mathrm{X}$ & $\mathrm{X}$ & $\checkmark$ & $\checkmark$ \\
\hline $\begin{array}{c}\text { Evaluation, in situ, of the } \\
\text { reactivity }\end{array}$ & $\mathrm{X}$ & $\mathrm{X}$ & $\checkmark$ & $\mathrm{X}$ & $\mathrm{X}$ \\
\hline Evaluation of the stickability & $\mathrm{X}$ & $\mathrm{X}$ & $\checkmark$ & $\mathrm{X}$ & $\mathrm{X}$ \\
\hline
\end{tabular}

\section{TEST PROCEDURE FOR INTUMESCENT PAINTS}

A general test procedure is shown for the characterization of intumescent paints on existing steel buildings. More details are in (Bilotta et al. 2015).

\subsection{Thickness tests}

The thickness measures should be carried out in order to measure the thickness of intumescent paints applied to the protected element to check the compliance between the design and the reality. Moreover, a detailed survey of the thickness allow to group the structural elements into homogeneous categories, to simplify the assessment of the structural behavior in fire conditions.

The evaluation of the thickness is regulated by the UNI EN 2808 which describes both investigation and data processing methods. Ultrasonic (Fig. 1) and optical (Fig. 2) instruments are widely used to measure the thickness. The first type has an ultrasonic transmitter and an ultrasonic receiver and the thickness of the paint is defined by measuring the propagation time of the waves through the layer to be measured. Non-invasiveness and high precision are advantages of using this instrument, but the process of instrument calibration, above all in situ, is extremely delicate. The optical instrument allows a direct measurement of the thickness practicing a slight cut on the painted element, up to reach the steel substrate. The blades are normalized and the thickness value can be read directly through a graduated microscope. The instrument is minimally invasive, and it can be considered a good tool to check the readings obtained by the ultrasonic one.

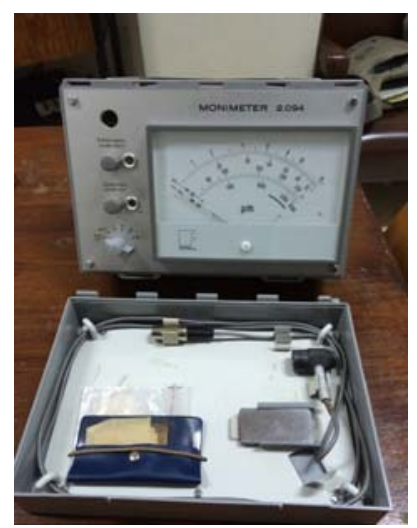

Fig. 1 - Ultrasonic instrument.

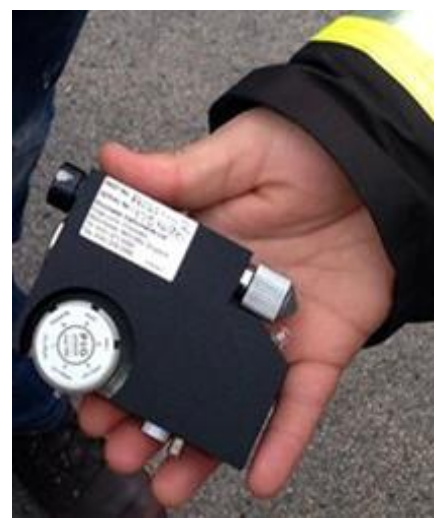

Fig. 2 - Optical instrument. 


\subsection{Adhesion tests}

The compatibility between the layers of the protective package (primer, coating and top coat) is checked through adhesion tests (UNI EN ISO 4624). In particular, the minimum tensile force necessary to cause the tearing of the layer of paint from the support (adhesion) or inside the layer of the weakest component (cohesion), is measured. The nature and the preparation of the substrate and the type of instrument used may influence the mechanical properties of the system. Therefore, it is necessary to refer to standardized procedures. However, these procedure concern new application of paints and should be adjusted for existing paints. The main steps followed for preparation and execution of the test are described below (Fig. 3).

Step 1 - surface preparation, to promote the bond between the dolly and the coating, degrease the dolly and the area of the coating to be tested using alcohol or acetone to remove any oil, moisture or dust.

Step 2 - application of adhesive, which must have cohesive and fixing properties greater than those of the coating under test, in order to obtain a rupture of the coating. The dolly should be gently push down to squeeze out excessive adhesive and remove it from around the edges of the dolly. Finally, wait for the time necessary for the drying of adhesive.

Step 3 - separation of test area: after adhesive drying, before starting the test, the paint around the dolly should be removed, in order to isolate a specific diameter test area. The methodology to apply the cut around the edges of the dolly depends on the mechanical properties of the paint system. Generally, a drill with a diameter about $1 \mathrm{~mm}$ larger than the diameter of the dolly can be used.

Step 4 - load application: this step consists of placing of the actuator on the dolly. The contact between the dolly and the actuator should be carefully checked. The force must be applied perpendicularly to the plane of coated support at a uniform speed, less than about $1 \mathrm{MPa} / \mathrm{s}$.

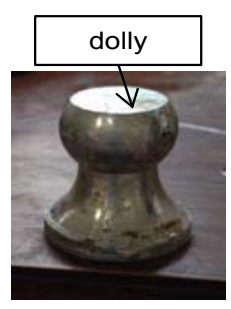

(a)

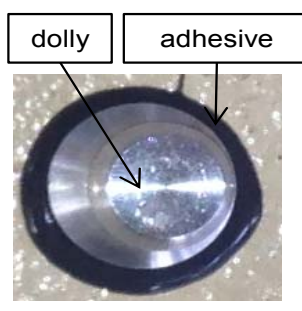

(b)

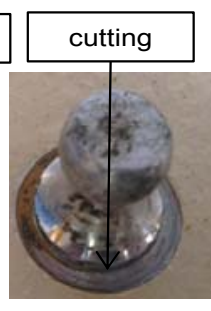

(c)

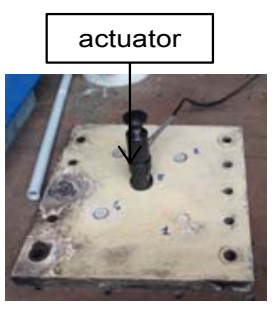

(d)

Fig. 3 - Steps of adhesion test.

\subsection{Furnace tests}

In general, the procedures for the assessment of the effectiveness of the protections on the structural elements are composed of two phases: the first one concerns the test in furnace, according to standard procedures, the second one is the processing of the experimental data to obtain the information necessary to extend the results to real cases. For reactive protection systems as intumescent paints, the regulation EN 13381-8 about the classification and certification of reactive protections, applied to steel elements should be used. The regulation provides tests in furnace of numerous samples loaded and not loaded, with different section factors and different thicknesses of intumescent coating, in order to characterize the protective material for its correct use (Nadjai et al., 2015). In this case, the purpose of the test in furnace is related to the characterization of the protective layer applied on existing steel elements of known geometry. Moreover, as it is an existing structure, the number of samples should be defined, to balance the requirement of an adequate characterization of paints and the need to limit the invasiveness of the investigations on the existing structure. The tests in furnace should be properly designed, through models (Wang et al., 2005) and analysis with dedicated software, to try to predict the temperatures reached in the elements subjected to the fire test (Schaumann et al., 2014). Finally, enough thermocouples should be applied on each sample in order to catch any signs of localized detachment of the paint. 


\section{CONCLUSIONS}

A possible general approach to assessment the fire safety of existing buildings is identified. Based on national and international regulations for existing buildings, the main paths, which the practitioner could take for fire vulnerability assessment of existing steel structures, are defined by considering various types of fire protection systems. The proposed approach is aimed to achieve a target level of knowledge of the structure, in order to properly evaluate the behaviour of the protective systems.

For structures protected with intumescent paints, an example of test procedure was shown. For some types of tests (thickness measurements, measures of adherence, measurements of reactivity) it was highlighted the possibility and the need to standardize the test procedures. In this regard, existing codes for the checks necessary for the commercialization of protective and its application to new buildings can be adapted for existing building. For the tests in furnace, it was highlighted that a proper design of fire test is necessary.

\section{ACKNOWLEDGMENTS}

The authors appreciated the contributions of Guido Parisi and Fabio Dattilo of the Italian National Fire Services. They would also like to thank Luca Ponticelli, Claudio Mastrogiuseppe and all the technicians of the Laboratory of the Central Directorate for Fire Prevention and Technical Safety of the Italian National Fire Services in Capannelle (RM) for assistance in carrying out the fire tests described briefly herein.

\section{REFERENCES}

Bilotta A., de Silva D., Nigro E., Ponticelli L., 2015. Tests on intumescent paints for fire protection of existing steel structures, in IFireSS_2015, 20-22 April 2015, Coimbra, Portugal.

CEE, Construction of European Community (1993). Interpretative Document No. 2: Safety in case of fire

EN 1993-1-2:2005 Eurocode 3- Design of steel structures - Part 1-2: General Rules - Structural fire design.

EN 1998-3:2005 Eurocode 8- Design of structures for earthquake resistance - Part 3: Assessment and retrofitting of buildings.

EN 1363-2-July 2001-Fire resistance tests. Alternative and additional procedures.

EN 13381-8 Test methods for determining the contribution to the fire resistance of structural members. Applied reactive protection to steel members.

EN 2808-March 2007 Paint and varnishes- Determination of film thickness.

EN ISO 4624-June 2006 Paint and varnishes- Pull-off test for adhesion.

EOTA- ETAG No 018- Progress file version November 2011- Guideline for European Technical Approval of fire protective products. PART 2 - Reactive coatings for fire protection of steel elements.

ENV 13381-4-November 2002-Test methods for determining the contribution to the fire resistance of structural members. Applied passive protection products to steel members.

Wald F., Strejček M., Tichá A. On bolted connection with intumescent coatings. http://people.fsv.cvut.cz/ wald/Clanky\%20v\%20Adobe\%20(Pdf)/083_Wald_Intumescent_painting_v6.pdf

Wang, Y., Goransson, U., Holmstedt, G. and Omrane, A., 2005. A model for prediction of temperature in steel structure protected by intumescent coating, based on tests in the cone calorimeter. Fire Safety Science 8: 235-246.

Nadjai A., Sanghoon H., Faris A., Petrou K., El Hadi, Naili A., 2015. Behavior of unprotected and protected cellular beams in fire conditions, in IFireSS_2015, 20-22 April 2015, Coimbra, Portugal.

Rush D. I., Bisby L. A., Jowsey A. Evaluating design guidance for intumescent fire protection of concrete filled steel hollow sections. Structures in Fire (SIF) Shanghai, China, 2014, p 1071-1078.

Schaumann P., Tabeling F. and Weisheim W., 2014. Thermal simulation of steel profiles with intumescent coating adjacent to space-enclosing elements, in - SiF'2014, 11 - 13 June 2014, Shanghai, China, p.121-128.

UNI 10898-1-May 2012- Fire proofing systems- Inspection modes for the installation. Part 1: Intumescent coating.

UNI 10898-2-October 2003- Fire proofing systems- Inspection modes for the installation. Part 2: Boards systems.

UNI 10898-3-October 2007- Fire proofing systems- Inspection modes for the installation. Part 3: Insulating sprayed systems. 